\title{
APLIKASI SISTEM INFORMASI GEOGRAFIS UNTUK PENENTUAN LOKASI PENGEMBANGAN BUDI DAYA LAUT DI TELUK EKAS, NUSA TENGGARA BARAT
}

\author{
I Nyoman Radiarta, Supriyono Eko Wardoyo, Bambang Priono, dan Ongko Praseno
}

\begin{abstract}
ABSTRAK
Pemilihan lokasi yang tepat merupakan salah satu syarat utama bagi keberhasilan pengembangan budi daya laut. Sehubungan dengan hal tersebut, penelitian ini bertujuan untuk mengaplikasikan SIG (Sistem Informasi Geografis) guna menganalisis lokasi ideal bagi pengembangan budi daya laut. Penelitian telah dilaksanakan di Teluk Ekas NTB pada bulan Juli dan September 2002. Pengamatan secara acak dengan teknik sederhana dan sistematik digunakan untuk menentukan lokasi titik pengamatan. Penentuan lokasi ideal pengembangan budi daya laut berdasarkan penggabungan beberapa faktor internal (kualitas perairan: parameter fisik dan parameter kimia) dengan menggunakan SIG serta memperhatikan beberapa faktor eksternal (penduduk, jalan, dll.). Dari hasil survai yang dilakukan, secara umum kualitas perairan masih dalam kisaran baik untuk kegiatan budi daya laut. Begitu pula dengan faktor eksternal, umumnya baik. Dari total area Teluk Ekas 5.313 ha terdapat 3.396 ha yang berpotensi untuk kegiatan budi daya. Sisanya adalah daerah dangkal/kering pada saat surut cukup rendah seluas 1.916 ha. Berdasarkan analisis SIG (penggabungan internal dan eksternal faktor) diperoleh lokasi seluas 1.576 ha yang ideal untuk pengembangan budi daya laut. Area tersebut direkomendasikan untuk budi daya ikan laut dengan keramba jaring apung (KJA).
\end{abstract}

\begin{abstract}
Application of Geographic Information System (GIS) for site selection of mariculture development in Ekas Bay, West Nusa Tenggara. By: I Nyoman Radiarta, Supriyono Eko Wardoyo, Bambang Priono, and Ongko Praseno
\end{abstract}

\begin{abstract}
Site selection is one of the main factors for mariculture development. Dealing with this situation, the aim of this research was attempted to use GIS application for site selection analysis in mariculture development. The research was done at Ekas Bay in July and September 2002. Simple random and systematic random sampling was used to allocate sampling points. The site selection was based on overlay of some internal factors (water quality: physical and chemical parameters) using GIS. Some external factors (road network, settlement, etc.) were also observed. Based on the survey, ranges of water quality values are generally still good for mariculture activities, and external factors such as road network and settlement are available for supporting mariculture activities in the bay. Ekas Bay has 5.313 ha in area, and of this, only 3.396 ha is potential for mariculture activities while the rest of 1.916 ha compresses of shallow waters area which are dry during low tides. Based on GIS analysis when it is overlaid between internal and external factors there is a area of 1.576 ha ideal for mariculture development and can be used for cage culture.
\end{abstract}

KEYWORDS: $\quad$ site selection, mariculture, GIS

\section{PENDAHULUAN}

Perairan Indonesia yang mempunyai garis pantai sepanjang $95.000 \mathrm{~km}$ dan jumlah pulau sebanyak 17.000 buah (Burke et al., 2002) serta beragamnya jenis ekosistem yang ada, di antaranya terumbu karang, padang lamun, mangrove, teluk, goba, selat, muara sungai, pantai landai berpasir, dan daratan pasang surut, merupakan peluang bagi pengembangan budi daya laut. Selain itu, dukungan pemerintah terhadap kegiatan ini sangat nyata yaitu dengan dikeluarkannya Keputusan Presiden Republik Indo- nesia No. 23 Tahun 1982 tentang pengembangan budi daya laut, diikuti oleh Surat Keputusan Menteri Pertanian No. 473/Kpts/Um/7/1982 tentang petunjuk pelaksanaan pengembangan budi daya laut di perairan Indonesia (Sulistijo \& Nontji, 1995).

Data potensi lahan perairan untuk pengembangan budi daya laut di Indonesia telah dilaporkan oleh Trensongrusmee et al. (1989) dalam Cholik et al. (1995). Nurjana et al. (1997) dalam Sudradjat et al. (2002) mengemukakan bahwa potensi untuk pengembangan budi daya laut berdasarkan

") Pusat Riset Perikanan Budidaya, Jakarta 
komoditas terdiri atas ikan, rumput laut, dan kekerangan/tiram. Hasil analisis tersebut menunjukkan area yang berpotensi untuk budi daya laut seluas 8,53 juta ha. Menurut Ramelan (1999), potensi perairan laut yang dapat dimanfaatkan untuk pengembangan usaha budi daya laut di Indonesia mencapai 10 juta ha yang terbagi atas potensi budi daya ikan 3 juta ha, kekerangan dan mutiara 5 juta ha, teripang 700.000 ha, dan rumput laut 1,85 juta ha. Sukadi (2002) mengemukakan bahwa potensi sumber daya lahan yang dapat dimanfaatkan untuk budi daya laut mencapai 24,528 juta ha; namun tingkat pemanfaatannya baru mencapai 0,0016\% (388 ha).

Ismail \& Pratiwi (2002) mengemukakan bahwa jenis-jenis perairan yang dapat digunakan untuk kegiatan budi daya laut di antaranya: teluk, teluk kecil (inlet), selat, perairan karang, goba (lagoon), pantai terbuka, dan laut lepas. Tentu saja setiap jenis perairan ini mempunyai keuntungan dan kerugian dalam pengembangannya. Berdasarkan kriteria yang dikemukakan, dalam penilaian lokasi maka teluk merupakan lokasi yang paling baik diikuti dengan perairan karang dan perairan selat.

Perencanaan pengembangan budi daya laut di Indonesia, masih banyak mengalami kesalahan. Salah satu penyebabnya adalah lingkungan perairan yang tidak cocok bagi kegiatan budi daya laut selain data parameter kualitas air yang tidak sesuai di lokasi tersebut untuk kegiatan budi daya (Ahmad, 2001). Oleh karena itu, agar kegiatan budi daya laut dapat berkembang dengan baik, diperlukan analisis penentuan lokasi yang sesuai serta didukung oleh analisis data yang baik dan benar bagi kondisi perairan yang ideal.

Dengan perkembangan teknologi secara umum dewasa ini, SIG (Sistem Informasi Geografis) merupakan salah satu pilihan dalam penentuan lokasi ideal untuk pengembangan budi daya laut. Hingga kini masih sedikit aplikasi SIG yang digunakan untuk penelitian bidang perikanan budi daya. Beberapa penelitian yang mengaplikasikan SIG bagi perikanan budi daya di antaranya Kapestky et al. (1987), Ross et al. (1993), dan Tarunamulia et al. (2001). SIG merupakan analisis secara spasial (keruangan) yang dapat memadukan beberapa data dan informasi tentang budi daya perikanan dalam bentuk lapisan (layer) yang nantinya dapat ditumpanglapiskan (overlay) pada data yang lain, sehingga menghasilkan suatu keluaran baru dalam bentuk peta tematik. Kemampuan ini merupakan kelebihan yang dimiliki oleh SIG dibandingkan dengan analisis secara tekstual.

Penelitian ini mencoba mengaplikasikan sistem informasi geografis (SIG) untuk menganalisis lokasi ideal bagi pengembangan budi daya laut di Indonesia dengan memadukan faktor internal dan eksternal. Hasil dari penelitian ini diharapkan dapat menjadi acuan dalam menentukan lokasi untuk pengembangan kegiatan budi daya laut di Indonesia.

\section{BAHAN DAN METODE}

Penelitian pemetaan lokasi bagi pengembangan budi daya laut ini telah dilakukan pada bulan Juli dan September 2002, dan mengambil lokasi di Teluk Ekas. Teluk Ekas terletak di bagian selatan Pulau Lombok Propinsi Nusa Tenggara Barat (NTB). Perairan ini secara administrasi masuk ke dalam dua kabupaten yaitu Kabupaten Lombok Timur dan Lombok Tengah; membujur dari barat ke timur di antara $116^{\circ} 23^{\prime}-116^{\circ} 29^{\prime}$ Bujur Timur dan di antara $8^{\circ} 49^{\prime}-8^{\circ}$ 55' Lintang Selatan. Perairan ini sangat berpotensi bagi pengembangan budi daya laut, karena perairannya terlindung dan relatif tenang. Selain itu didukung pula oleh pemerintah daerah yang dalam perencanaan tata ruang wilayah Pulau Lombok (NTB) menetapkan Teluk Ekas sebagai lokasi pengembangan budi daya laut. Teluk Ekas dengan luas 5.313 ha dan panjang garis pantai $44 \mathrm{~km}$ masuk ke dalam empat desa yaitu Desa Pamongkong, Desa Sukaraja, Desa Batunampar (Kabupaten Lombok Timur), dan sebagian kecil di Desa Awang (Kabupaten Lombok Tengah). Gambar 1 menyajikan tampilan umum lokasi penelitian dan distribusi lokasi pengamatan di Teluk Ekas.

Di Teluk Ekas terdapat dua pulau kecil yaitu Gili Linus yang lokasinya lebih dekat dengan Dusun Batunampar dan Gili Areng dekat dengan Dusun Ujung. Di salah satu sisi teluk terdapat area terumbu karang yang sampai saat ini merupakan daerah suaka yang dilindungi untuk kegiatan penangkapan ikan.

Metode yang dipakai dalam penelitian ini adalah metode survai yang dirancang berdasarkan sistem informasi geografis (SIG). Penentuan titik pengamatan dirancang dengan dua teknik yaitu: simple random sampling (Clark \& Hosking, 1986; Burrough \& McDonnell, 1998) yang diterapkan untuk penentuan titik pengamatan di lapangan dan penentuan posisi dengan menggunakan alat GPS (Global Positioning System). Systematic random sampling (Clark \& Hosking, 1986; Morain, 1999) dilakukan pada titik pengamatan yang dirancang dengan jarak $1 \mathrm{~km}$ (arah vertikal dan horizontal) dan posisinya telah ditentukan sebelum ke lapangan. GPS dalam Systematic random sampling di lapangan ini hanya berfungsi sebagai tracking. Sebanyak 56 titik pengamatan telah dikumpulkan dengan menggunakan metode di atas untuk pengumpulan data kualitas perairan. Sebaran titik pengamatan dapat dilihat pada Gambar 1 .

Data yang dikumpulkan dalam penelitian ini terdiri atas data primer dan data sekunder. Data primer yang 


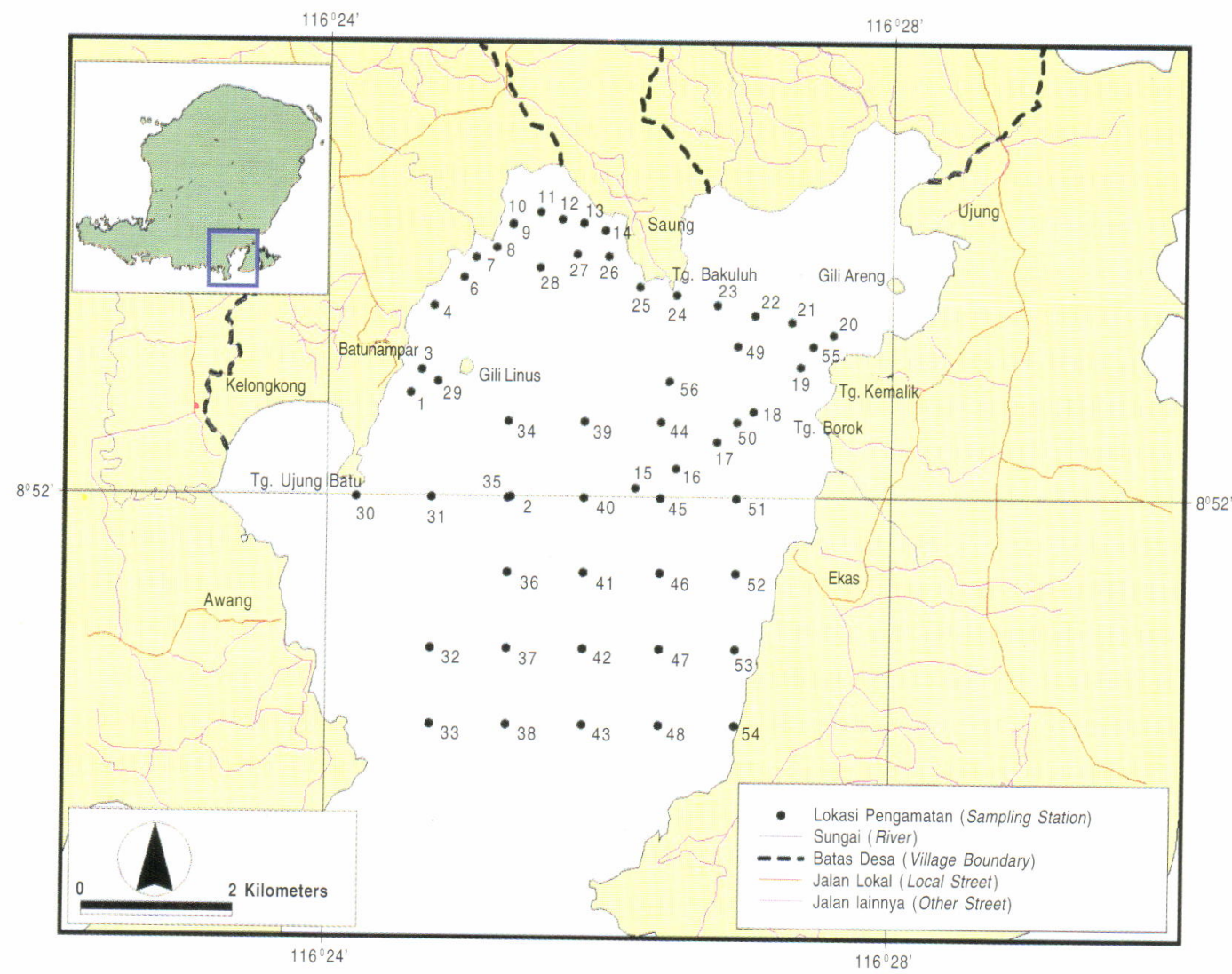

Gambar 1. Tampilan umum lokasi penelitian di Teluk Ekas dan distribusi lokasi pengamatan kualitas perairan Figure 1. General features of Ekas Bay and distribution of water quality sampling points

dikumpulkan meliputi: data kualitas perairan (fisik, kimia, tanah dasar, dan kesuburan perairan), jumlah penduduk, dan jenis kegiatan budi daya perikanan yang ada. Sedangkan data sekunder berupa peta dasar lokasi penelitian. Peta dasar ini didigitasi dari peta rupa bumi skala 1:25.000 keluaran Bakosurtanal tahun 1995. Informasi yang diambil dari peta rupa bumi ini meliputi: garis pantai, sungai, jaringan transportasi (jalan), batas desa, batas kabupaten, sebaran penduduk, mangrove, dan kegiatan perikanan yang ada (tambak ikan / tambak penggaraman). Informasi yang diambil ini nantinya merupakan lapisan-lapisan dalam analisis spasial penentu lokasi pengembangan budi daya laut. Diagram alur analisis spasial penentuan lokasi pengembangan budi daya laut di Teluk Ekas dapat dilihat pada Gambar 2.

Data lapangan yang dikumpulkan berupa titik (point information) yang mengandung informasi kualitas perairan. Untuk menganalisis secara spasial titik yang berisi informasi tersebut terlebih dahulu harus dilakukan interpolasi. Metode ini merupakan suatu metode dalam pengolahan data titik menjadi area (polygon). Cara interpolasi titik menjadi area menggunakan metode Nearest Neighbor (Burrough \& McDonnell, 1998; Morain, 1999). Dari hasil interpolasi masing-masing parameter kualitas perairan yang diperoleh kemudian ditentukan area yang sesuai bagi pengembangan budi daya laut berdasarkan nilai ideal untuk budi daya laut. Nilai ideal kualitas perairan yang digunakan untuk pemilihan lokasi mengacu pada metode pemilihan lokasi bagi pembesaran ikan dalam keramba jaring apung yang dikemukakan oleh Imanto et al. (1995); Ahmad et al. (1995); Beveridge, 1996; dan Ismail et al. (1998) (Tabel 1).

Lokasi ideal pengembangan budi daya laut dihasilkan setelah seluruh data faktor internal digabungkan / tumpang lapis (overlay) dan didukung dengan faktor eksternal (Gambar 2).

\section{HASIL DAN BAHASAN}

Kondisi perairan Teluk Ekas sangat dipengaruhi oleh pola pasang surut harian yang terjadi. Berdasarkan hasil pengamatan di lapangan dan didukung oleh studi pustaka (Nontji, 1993), pola pasang surut yang terjadi di Teluk Ekas adalah campuran yang cenderung ke harian ganda yaitu terjadi dua kali pasang dan surut. Keadaan air surut terjadi pada pagi dan sore hari. Kondisi pasang surut ini sangat mempengaruhi luasan area yang dapat digunakan untuk kegiatan budi daya laut. Lampiran 1 
FAKTOR EKSTERNAL EXTERNAL FACTOR

FAKTOR INTERNAL INTERNAL FACTOR

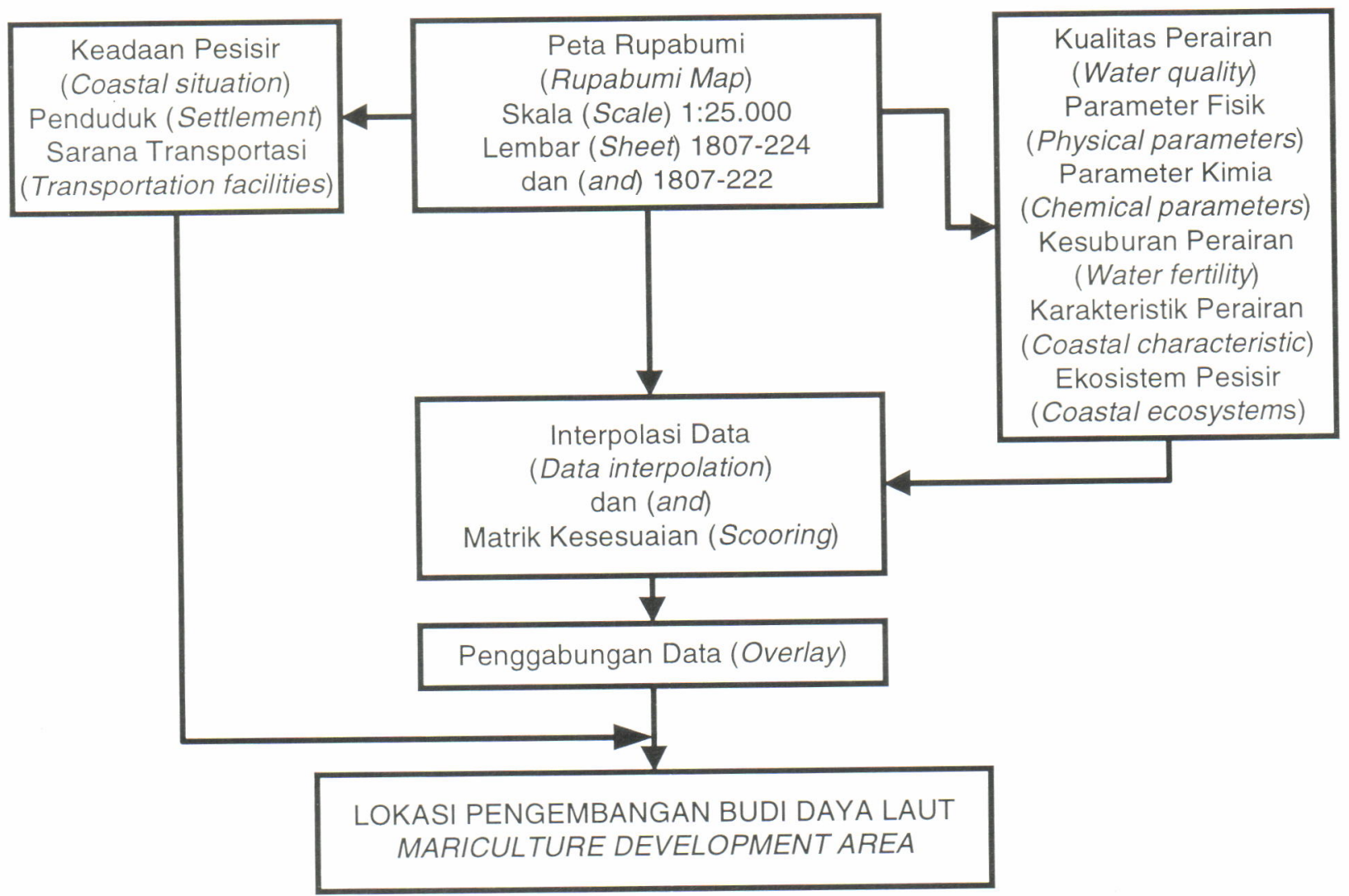

Gambar 2. Diagram alur penentuan lokasi pengembangan budi daya laut

Figure 2. Flow chart of site selection method for mariculture development

Tabel 1. Nilai ideal parameter kualitas perairan pemilihan lokasi budi daya laut Table 1. Water quality ideal value for mariculture site selection

\begin{tabular}{lcc}
\hline \multicolumn{1}{c}{$\begin{array}{c}\text { Parameter Kualitas Perairan } \\
\text { Water quality parameters }\end{array}$} & $\begin{array}{c}\text { Satuan } \\
\text { Unit }\end{array}$ & $\begin{array}{c}\text { Nilai Ideal } \\
\text { Ideal value }\end{array}$ \\
\hline Kedalaman (Depth) & meter & $7-25$ \\
Kecerahan (Transparency) & meter & $>3$ \\
Salinitas (Salinity) & $\mathrm{ppt}$ & $>30$ \\
Oksigen Terlarut (Dissolved Oxygen) & $\mathrm{mg} / \mathrm{L}$ & $>7$ \\
pH & & $>7$ \\
Suhu Air (Water temperature) & ${ }^{\circ} \mathrm{C}$ & $26-32$ \\
Arus Air (Water current) & $\mathrm{m} /$ menit & $4-8$ \\
Tanah Dasar (Substrate) & - & berpasir (sandy) \\
\hline
\end{tabular}

menunjukkan gambaran umum perairan Teluk Ekas pada saat air pasang dan surut. Pada saat surut terendah, total area yang berpotensi untuk budi daya laut adalah sebesar 3.396 ha atau sekitar $64 \%$ dari total area Teluk Ekas, sisanya 1.916 ha $(36 \%)$ berupa daerah dangkal/kering yang saat surut terendah sebagian lokasinya ditumbuhi oleh padang lamun dan pecahan-pecahan batu karang. Secara jelas kondisi tersebut dapat dilihat pada Gambar 3.

Faktor pasang surut ini menjadi sangat penting dalam analisis lokasi, karena berpengaruh terhadap luasan area yang dapat digunakan untuk kegiatan budi 


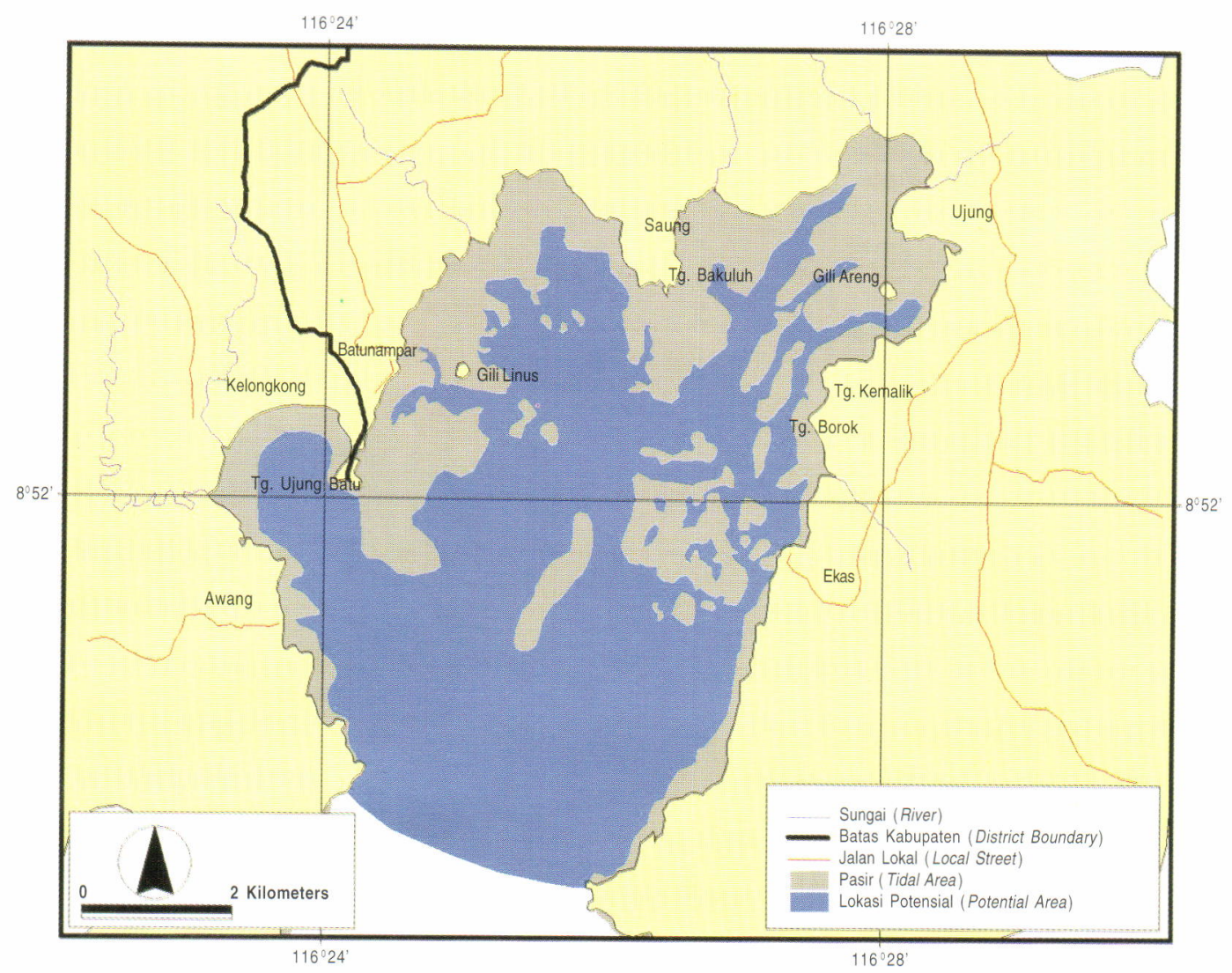

Gambar 3. Area untuk analisis pemilihan lokasi budi daya laut

Figure 3. Area for analysis of mariculture site selection

daya laut. Berdasarkan pola pasang surut tersebut, maka luasan yang berpotensi untuk kegiatan budi daya laut adalah sebesar 3.396 ha.

\section{Faktor Internal (Kondisi Kualitas Perairan)}

Secara umum kualitas perairan permukaan di 56 titik pengamatan di perairan Teluk Ekas masih dalam batas toleransi kegiatan budi daya laut (Lampiran 2). Sampling dilakukan pada pagi jam 09:30 sampai dengan sore jam 16:30. Perbedaan waktu sampling ini juga sangat berpengaruh pada beberapa para- meter kualitas perairan di antaranya suhu air dan kecepatan arus. Kisaran nilai kualitas perairan yang diperoleh dari hasil pengamatan di lapangan secara ringkas disajikan pada Tabel 2.

Dari pengamatan kualitas perairan kecepatan arus memiliki nilai yang cukup tinggi (mencapai $18 \mathrm{~m} /$ menit) yang terukur di stasiun 35,52 , dan 53 . Hal ini disebabkan pengukurannya dilakukan pada saat air pasang atau surut. Data kualitas perairan yang sudah diinterpolasi dengan metode Nearest Neighboruntuk menjadi area (polygon) dan dianalisis secara spasial

Tabel 2. Kisaran nilai kualitas perairan di Teluk Ekas

Table 2. Range value of water quality at Ekas Bay

\begin{tabular}{lccc}
\hline \multicolumn{1}{c}{$\begin{array}{c}\text { Parameter } \\
\text { Parameters }\end{array}$} & $\begin{array}{c}\text { Satuan } \\
\text { Unit }\end{array}$ & $\begin{array}{c}\text { Kisaran nilai } \\
\text { Range value }\end{array}$ & $\begin{array}{c}\text { Nilai ideal } \\
\text { Ideal value }\end{array}$ \\
\hline Kedalaman (Depth) & meter & $0.5-37.5$ & $7-25$ \\
Kecerahan (Transparency) & meter & $0.5-8$ & $>3$ \\
Suhu Air (Water temperature) & ${ }^{\circ}$ C & $24-30$ & $26-32$ \\
Arus Air (Water current) & $\mathrm{m} /$ menit & $1-18$ & $4-8$ \\
$\mathrm{pH}$ & - & $7.5-8.5$ & $>7$ \\
Salinitas (Salinity) & $\mathrm{ppt}$ & $25-41$ & $>30$ \\
\hline
\end{tabular}


memberikan tampilan yang dapat dilihat pada Gambar 4.

Selain data kualitas perairan, di beberapa titik pengamatan juga dilakukan pengambilan data tekstur tanah dasar perairan (Tabel 3). Data ini sangat erat
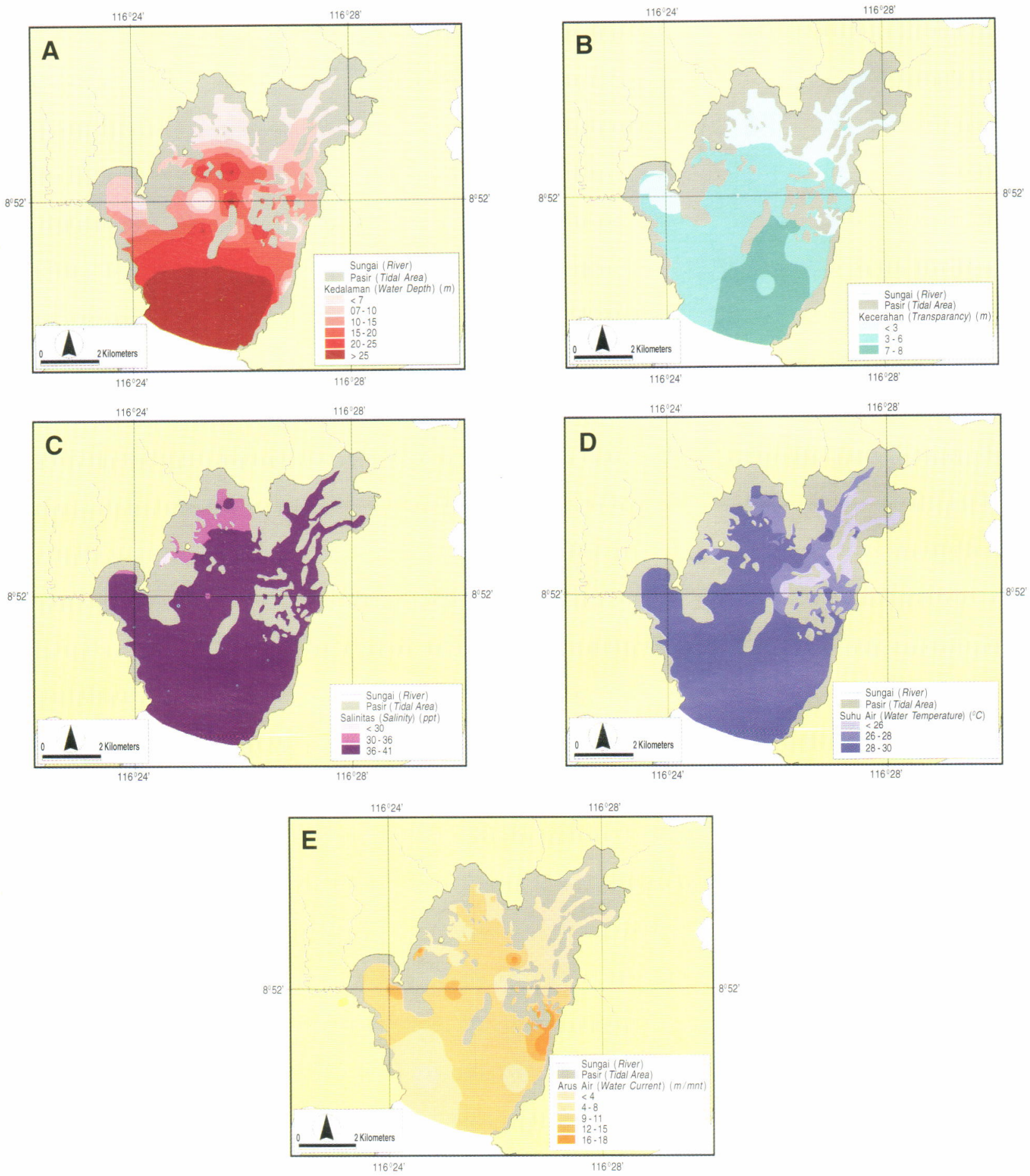

kaitannya dengan kemungkinan untuk penempatan KJA dan desain konstruksi KJA terutama untuk tipe jangkar yang akan dipakai. Ismail et al. (1998) mensyaratkan bahwa tekstur dasar perairan yang berpasir sangat ideal untuk daerah penempatan KJA,

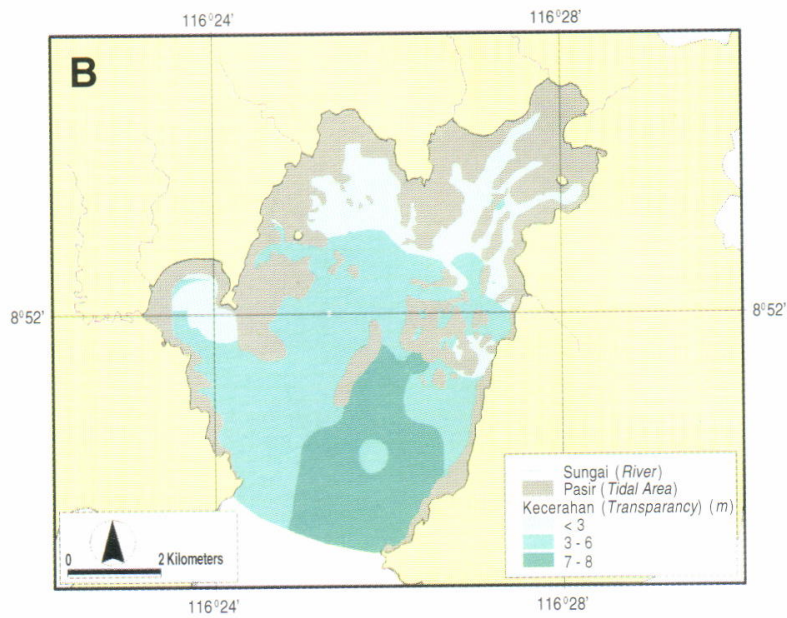

116028

Gambar 4. Sebaran spasial kualitas perairan di Teluk Ekas: (a) kedalaman, (b) kecerahan, (c) salinitas, (d)

Gambar 4. Sebaran spasial kualitas perairan di Teluk Ekas: (a) kedalaman, (b) kecerahan, (c) salinitas, (d) suhu air, (e) arus air

Figure 4. Spatial distribution of water quality at Ekas Bay: (a) water depth, (b) transparency, (c) salinity, (d) water temperature, (e) water current 
Tabel 3. Tipe tekstur tanah dasar perairan beberapa lokasi pengamatan di Telùk Ekas Table 3. Substrate types some sampling points at Ekas Bay

\begin{tabular}{cccc}
\hline \multirow{2}{*}{$\begin{array}{c}\text { Lokasi Pengamatan } \\
\text { Sampling Station }\end{array}$} & \multicolumn{3}{c}{ Tanah (Substrate) (\%) } \\
\cline { 2 - 4 } & $\begin{array}{c}\text { Pasir } \\
\text { (Sand) }\end{array}$ & $\begin{array}{c}\text { Debu } \\
\text { (Dust) }\end{array}$ & $\begin{array}{c}\text { Liat } \\
\text { (Clay) }\end{array}$ \\
\hline 1 & 34.2 & 28.1 & 37.8 \\
2 & 69.3 & 29.1 & 1.6 \\
3 & 71.8 & 26.5 & 1.7 \\
4 & 70.4 & 28.4 & 1.2 \\
6 & 71.6 & 27.0 & 1.4 \\
7 & 72.4 & 26.4 & 1.3 \\
8 & 65.3 & 32.5 & 2.2 \\
9 & 69.1 & 29.3 & 1.6 \\
10 & 68.5 & 29.7 & 1.9 \\
11 & 74.4 & 24.2 & 1.4 \\
13 & 69.9 & 28.9 & 1.2 \\
\hline
\end{tabular}

dan seluruh titik pengamatan menunjukkan bahwa sangat ideal bagi lokasi pengembangan KJA.

\section{Faktor Eksternal}

Penduduk dan infrastruktur penunjang (di antaranya jaringan transportasi, listrik, ketersediaan bahan) merupakan faktor eksternal yang menjadi perhatian dalam analisis spasial pengembangan budi daya laut. Penduduk merupakan faktor eksternal yang penting sehubungan dengan penyediaan tenaga kerja dan keamanan bagi kegiatan budi daya laut. Jumlah penduduk di beberapa dusun pantai sekitar Teluk Ekas secara berturut-turut adalah: Dusun Ekas: $300 \mathrm{KK}$, Ujung: 225 KK, Saung: 50 KK, dan Batunampar: 280 KK. Sebaran pemukiman di sekitar Teluk Ekas dapat dilihat pada Gambar 5.

Jaringan jalan yang terdapat di lokasi merupakan faktor pendukung untuk kemudahan mencapai lokasi (assessibilitas), transportasi bahan (benih, pakan, dan bahan KJA), maupun untuk transportasi produksi

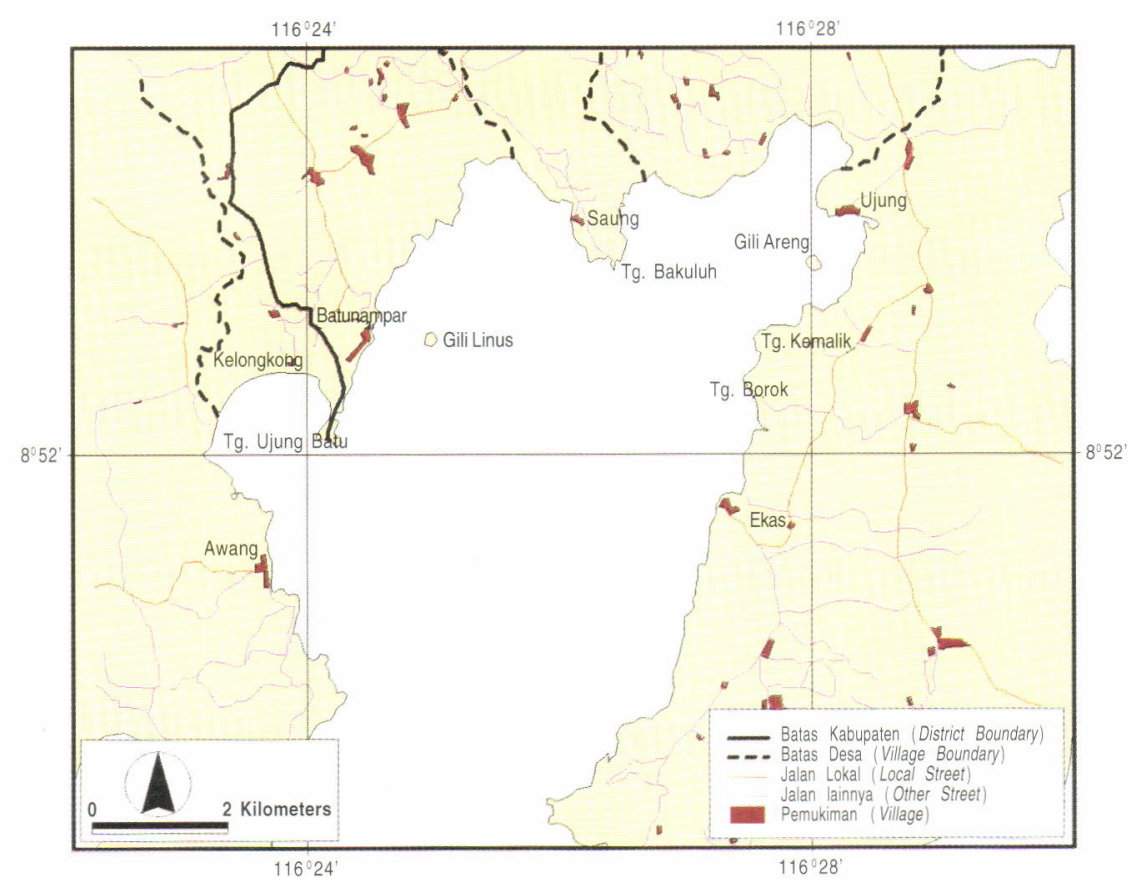

Gambar 5. Pemukiman dan jaringan jalan di sekitar Teluk Ekas

Figure 5. Human settlements and transportation network around Ekas Bay 
perikanan. Jaringan jalan (jalan lokal) yang bisa dilalui oleh kendaraan roda empat yaitu untuk lokasi Dusun Batunampar, Ujung, Saung (namun perlu sedikit perbaikan demi kenyamanan) dan Dusun Ekas (Gambar 5). Ketersediaan bahan untuk pengembangan budi daya laut di Teluk Ekas cukup mudah, begitu pula dengan ketersediaan sarana penerangan (listrik).

\section{Kegiatan Budi Daya Perikanan}

Kegiatan budi daya di perairan Teluk Ekas telah berkembang dengan cukup baik, terbukti dengan banyaknya kegiatan budi daya yang ditemukan. Jenis kegiatan yang paling banyak dijumpai yaitu budi daya rumput laut dengan sistem terapung (long line) dan sistem rakit. Keramba lobster juga ditemukan di beberapa lokasi (dusun), begitu pula dengan budi daya ikan dalam KJA. Jenis kegiatan budi daya laut ini menyebar di sekitar dusun-dusun yang berada di Teluk Ekas yaitu Dusun Ekas, Ujung, Saung, dan Batunampar (Tabel 4). Selain budi daya ikan di laut, ke arah daratan juga ditemui kegiatan budi daya tambak bandeng dan kegiatan penggaraman seperti terlihat pada Gambar 6 . Total area budi daya tambak adalah 97 ha, yang tersebar di tiga desa yang mengelilingi Teluk Ekas yaitu Desa Batunampar, Pamongkong, dan Semayang. Demikian juga kegiatan penggaraman tersebar di seluruh desa pantai dengan Iuasan mencapai 149 ha.

Untuk menjaga kelestarian sumber daya laut di Teluk Ekas dijumpai juga adanya area konservasi (suaka) perikanan yang letaknya dekat dengan Tanjung Barok dan Tanjung Kemalik. Area suaka seluas 1 ha ini terbentang di perairan karang. Suaka perikanan ini terbagi atas zona inti dan zona penyangga. Di dalam zona inti tidak diperbolehkan ada kegiatan apapun sedangkan untuk zona penyangga hanya diperbolehkan melakukan budi daya laut namun tidak untuk menangkap ikan atau mengambil batu / pasir. Nama suaka tersebut adalah "Sepak Kokok" yang artinya "Teguran Keras". Suaka ini didirikan sejak tahun 2001 di bawah pengelolaan KPPL (Komuniti Pengelola Perikanan Laut).

\section{Lokasi Pengembangan Budi Daya Laut}

Lokasi ideal pengembangan budi daya laut yang diperoleh dari penggabungan analisis faktor internal dan faktor eksternal adalah seluas 1.576 ha (Gambar 7). Luasan tersebut hanya $46 \%$ dari total area Teluk Ekas 3.396 ha tidak termasuk area pasir pada saat surut terendah. Berdasarkan kriteria yang digunakan untuk menentukan lokasi ideal pengembangan budi daya laut yang mengacu pada metode pemilihan

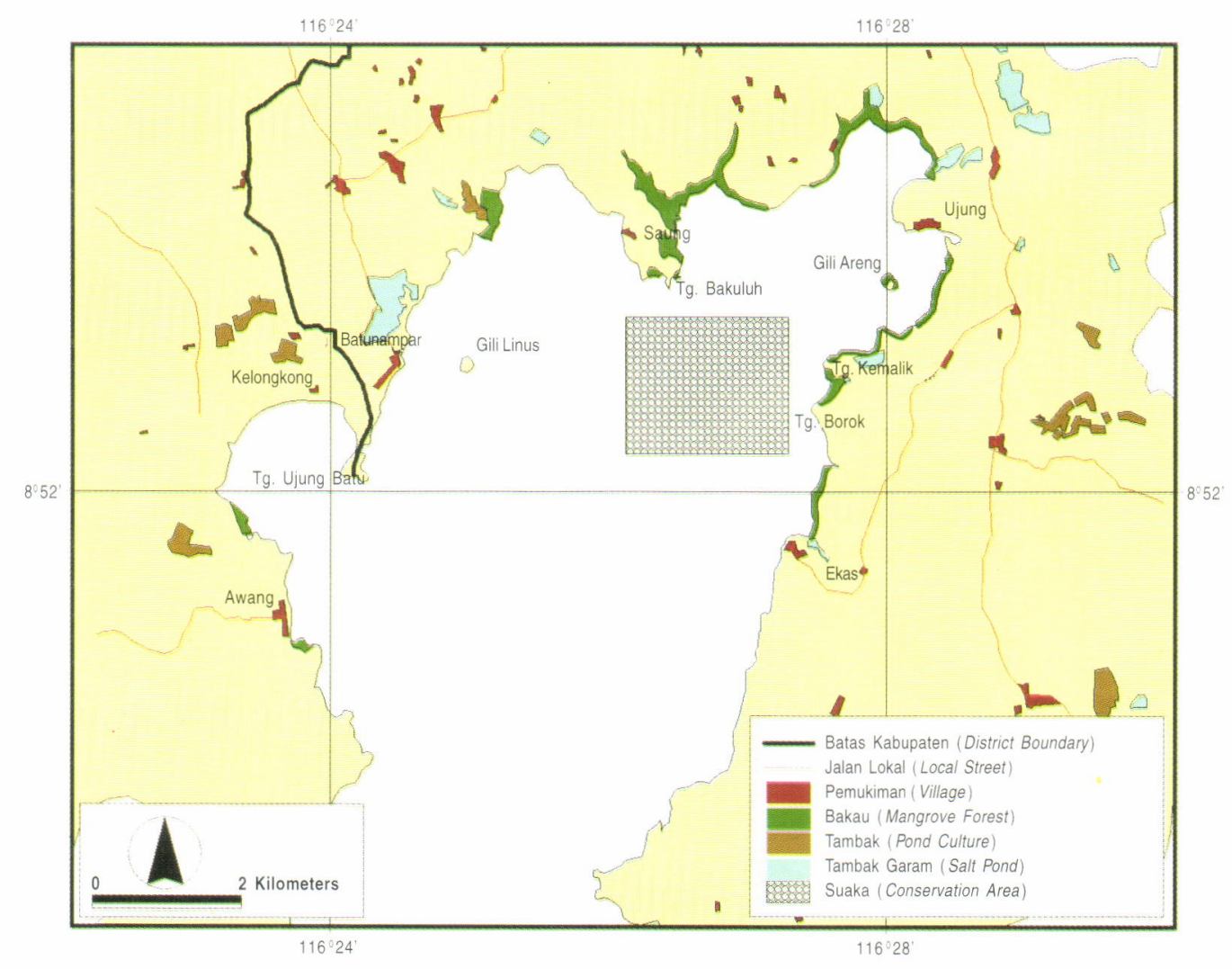

Gambar 6. Jenis kegiatan budi daya yang ada di sekitar Teluk Ekas

Figure 6. Kinds of aquaculture activities present at Ekas Bay and its vicinity 
lokasi bagi pembesaran ikan dalam keramba jaring apung, maka kegiatan budi daya yang direkomendasikan berdasarkan hasil analisis adalah kegiatan budi daya ikan laut dengan keramba jaring apung (KJA).

Untuk pengembangan usaha yang berkelanjutan, maka potensi yang ada sekiranya tidak dimanfaatkan seluruhnya, harus disediakan area yang fungsinya sebagai penyangga. Teluk Ekas dengan luasan ideal pengembangan 1.576 ha dapat dimanfaatkan untuk budi daya ikan dalam KJA mencapai 31.511 unit (atau seluas 79 ha). Dengan pertimbangan bahwa 1 ha lahan budi daya dapat dimanfaatkan secara efektif untuk 20 unit KJA (5\% dari luasan ideal), di mana 1 unit KJA terdiri atas 4 keramba dengan ukuran per keramba 2,5 x 2,5 x 3,5 m³ (Imanto, 2000). Untuk padat tebar ikan dapat mengacu pada Imanto (2000) yang mengemukakan bahwa untuk budi daya ikan kerapu, padat tebar yang optimal dapat mencapai 20 ekor/ $\mathrm{m}^{3}$, dengan menggunakan KJA ukuran 2,5 x 2,5 × 3,5 $\mathrm{m}^{3}$.

Tabel 4. Jenis kegiatan budi daya laut di sekitar Teluk Ekas

Table 4. Aquaculture activities at around Ekas Bay

\begin{tabular}{|c|c|}
\hline Dusun (Village) & Kegiatan budi daya laut (Mariculture activities) \\
\hline Ekas & $\begin{array}{l}149 \text { unit keramba lobster dan } 2.106 \text { unit } \\
\text { budi daya rumput laut (sistem rakit) }\end{array}$ \\
\hline Ujung & $\begin{array}{l}15 \text { unit keramba lobster dan } 100 \text { unit } \\
\text { budi daya rumput laut (sistem long line) }\end{array}$ \\
\hline Saung & $\begin{array}{l}\text { KJA ikan/lobster (10 orang) dan } 134 \text { unit } \\
\text { budi daya rumput laut (sistem rakit) }\end{array}$ \\
\hline Batunampar & $\begin{array}{l}\text { KJA ikan karang; } 70 \text { rakit budi daya lobster; } 1.000 \text { rakit } \\
\text { budi daya rumput laut (sistem rakit) }\end{array}$ \\
\hline
\end{tabular}

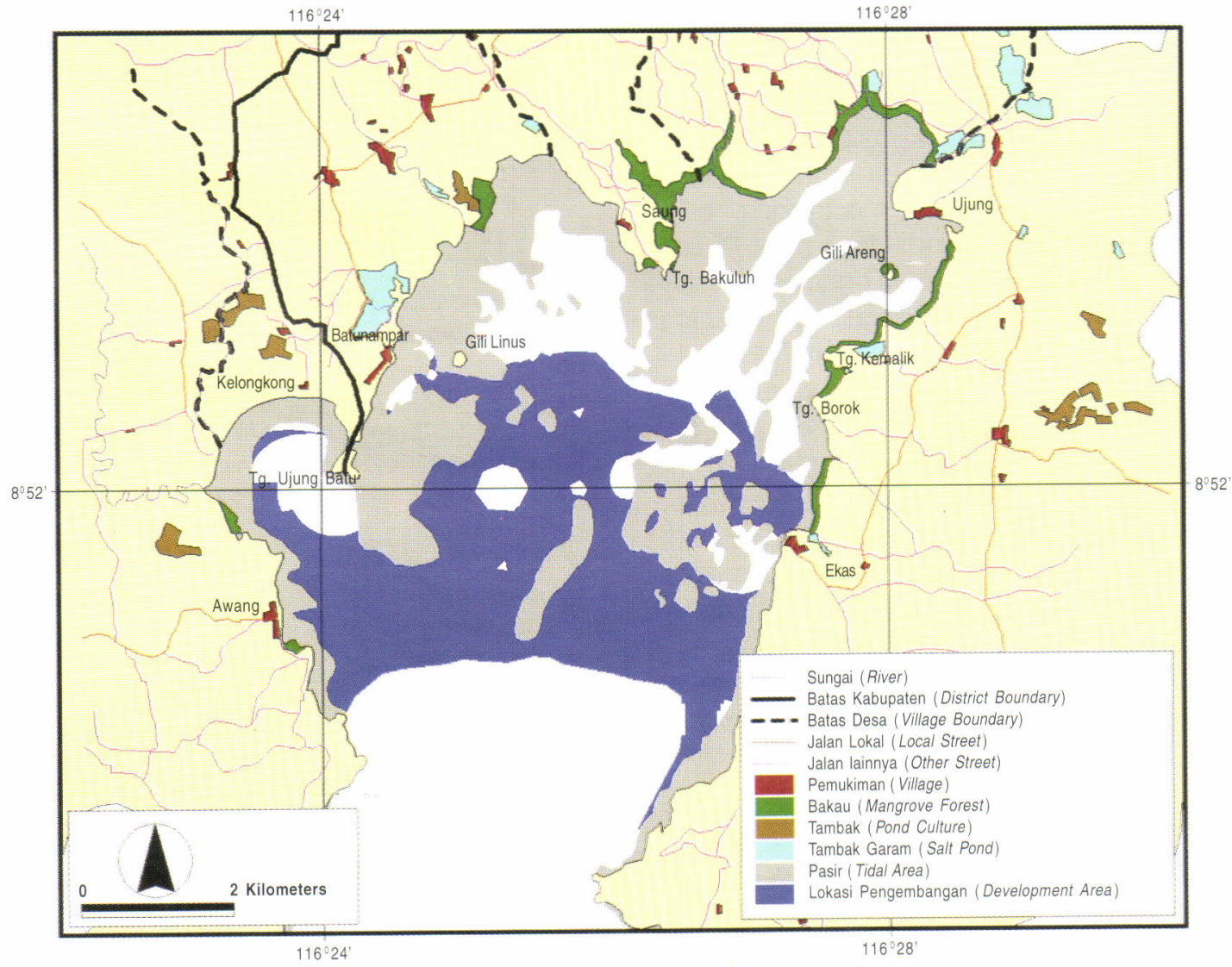

Gambar 7. Lokasi ideal pengembangan budi daya laut di Teluk Ekas

Figure 7. Ideal site for mariculture development at Ekas Bay 


\section{KESIMPULAN}

Berdasarkan analisis faktor internal yang mencakup beberapa parameter kualitas perairan menunjukkan bahwa hampir semua nilai kualitas perairan yang diperoleh memenuhi syarat untuk kegiatan budi daya laut. Kondisi pasang surut di Teluk Ekas sangat mempengaruhi luasan yang akan dianalisis, yaitu luasan yang masih tergenang air pada saat surut terendah adalah 3.396 ha sedangkan area yang tidak tergenang air adalah: 1.916 ha.

Faktor eksternal yang diperhatikan pada penelitian ini adalah ketersediaan jalur transportasi (jalan), penduduk, dan ketersediaan listrik serta bahan untuk budi daya. Faktor-faktor ini umumnya dapat dipenuhi. Jalan yang dapat digunakan untuk menuju ke Teluk Ekas dapat mencapai Dusun Batunampar, Saung, Ujung, dan Dusun Ekas, sedangkan keberadaan penduduk hampir tersebar merata di sekitar dusun pantai.

Penggabungan (overlay) dari faktor internal dan eksternal dengan menggunakan SIG menunjukkan bahwa luasan yang ideal untuk pengembangan budi daya laut terutama untuk kegiatan budi daya ikan laut (tahap pembesaran) adalah sebesar 1.576 ha. Luas tersebut untuk beberapa lokasi umumnya telah dimanfaatkan untuk kegiatan budi daya ikan laut dengan keramba jaring apung (KJA).

\section{SARAN}

1. Penelitian ini merupakan tahap awal dalam menentukan lokasi ideal. Disarankan untuk penelitian lebih jauh mengenai faktor-faktor yang berpengaruh pada pengembangan budi daya laut secara berkelanjutan (time series), sehingga selain lokasi ideal untuk pengembangan budi daya laut, juga dapat dihasilkan zonasi perikanan budi daya laut.

2. Penelitian ini hanya memanfaatkan teknologi SIG dan belum menggunakan data penginderaan jauh (inderaja, contohnya Landsat ETM+). Untuk penilitian selanjutnya disarankan memadukan antara data inderaja, sistem informasi geografis (SIG), dan data lapangan, sehingga akan memberikan hasil yang lebih baik dalam penentuan lokasi untuk budi daya, karena data inderaja akan memberikan gambaran umum lokasi yang terkini yang merupakan data masukan bagi SIG yang didukung pula oleh data lapangan (data atribut).

\section{UCAPAN TERIMA KASIH}

Pada kesempatan ini penulis mengucapkan terima kasih kepada semua anggota tim, baik dari Pusat Riset Perikanan Budidaya; Balai Riset Perikanan Budidaya Air Tawar, Bogor; Instalasi Riset Budidaya Ikan Hias Air Tawar, Depok; dan Loka Riset Pemacuan
Stok Ikan, Jatiluhur yang telah membantu dalam pelaksanaan penelitian ini.

\section{DAFTAR PUSTAKA}

Ahmad, T., A. Rukyani, dan A. Wijono. 1995. Teknik budidaya laut dengan keramba jaring apung dalam Sudradjat et al., 1995. Prosiding Temu Usaha Pemasyarakatan Teknologi Keramba Jaring Apung bagi Budidaya Laut. Puslitbang Perikanan, Badan Litbang Pertanian. p. 69--87.

Ahmad, T. 2001. Analisis Pengembangan Sea Farming di Indonesia. Warta Penelitian Perikanan Indonesia. Vol. 7 No. 1. p. 9--14.

Beveridge, M.C.M. 1996. Cage Aquaculture (Second Edition). Fishing News Books LTD. Farnham, Surrey, England. $352 \mathrm{pp}$.

Burrough, P.A. and R.A. McDonnel. 1998. Principle of Geographical Information Systems. Oxford University Press. 327 pp.

Burke, L., E. Selig, and M. Spalding. 2002. Reef at Risk in Southeast Asia. World Resources Institute. 72 pp.

Cholik, F., A. Sudradjat, dan P.T. Imanto. 1995. Peluang Agribisnis Budidaya Laut di Kawasan Timur Indonesia dalam Sudradjat et al., 1995. Prosiding Temu Usaha Pemasyarakatan Teknologi Keramba Jaring Apung bagi Budidaya Laut. Puslitbang Perikanan, Badan Litbang Pertanian. p. 136--156.

Clark, W.A.V. and P.L. Hosking. 1986. Statistical Methods for Geographers. John Wiley \& Sons, Inc. 513 pp.

Imanto, P.T., N. Listyanto, dan B. Priono. 1995. Desain dan konstruksi keramba jaring apung untuk budidaya ikan laut dalam Sudradjat et al., 1995. Prosiding Temu Usaha Pemasyarakatan Teknologi Keramba Jaring Apung bagi Budidaya Laut. Puslitbang Perikanan, Badan Litbang Pertanian. p. 216--230.

Imanto, P.T. 2000. Budidaya Ikan Laut. Workshop Pengelolaan Sumber Daya Perikanan Berbasis Komunitas 20--22 November 2000. Lombok Timur. $19 \mathrm{pp}$.

Ismail, W., S.E.Wardoyo, dan B. Priono. 1998. LokasiLokasi Potensial bagi Panti Benih Terapung Ikan Karang di Selatan P. Bintan dan Karimun Jawa. Jurnal Penelitian Perikanan Indonesia. Vol. IV No. 1. p. 36$-46$.

Ismail, W. dan E. Pratiwi. 2002. Budidaya Laut Menurut Tipe Perairan. Warta Penelitian Perikanan Indonesia. Vol. 8 No. 2. p. 8--12.

Kapestky, J.M., L. McGregor, and H. Nanne. 1987. A geographical information system and satellite remote sensing to plan for aquaculture development: A FAO - UNEP/GRID Cooperative Study in Costa Rica. FAO Fish. Tech. Pap. (287):51 pp.

Morain, S. 1999. GIS Solution in Natural Resource Management: Balancing the Technical-Political Equation. OnWord Press. USA. 361 pp.

Nontji, A. 1993. Laut Nusantara. Penerbit Djambatan. $362 \mathrm{pp}$.

Ramelan, T. 1999. Rencana pengembangan budi daya laut di Indonesia. Dalam Sudradjat et al., 1999. 
Prosiding Seminar Nasional Penelitian dan Diseminasi Teknologi Budi Daya Laut dan Pantai. Puslitbang Perikanan, Badan Litbang Pertanian. p. 17-21.

Ross, L.G., E.A. Mendoza, and M.C.M. Beveridge. 1993. The use of geographical information systems for site selection for coastal aquaculture. Aquaculture. Vol. 112, No. 2--3, p. 165--78.

Sudradjat, A., W. Ismail, dan P.T. Imanto. 2002. Penelitian dan Pengembangan Marikultur di Indonesia. Dalam Cholik, F., E.S. Heruwati, A. Jauzi, dan P.I. Basuki. Menggapai Cita-Cita Luhur: Perikanan Sebagai Sektor Andalan Nasional. Ikatan Sarjana Perikanan Indonesia. p. 210--228.

Sukadi, M.F. 2002. Pengembangan Perikanan Budidaya untuk Mendukung Pembangunan Nasional. Rapat
Kerja Teknis Pusat Riset Perikanan Budidaya, Surabaya 25--26 November 2002. 13 pp.

Sulistijo dan A. Nontji. 1995. Potensi lingkungan laut untuk kegiatan budidaya. Dalam Sudradjat et al., 1995. Prosiding Temu Usaha Pemasyarakatan Teknologi Keramba Jaring Apung bagi Budidaya Laut. Puslitbang Perikanan, Badan Litbang Pertanian. p. 54-68.

Tarunamulia, A. Mustafa, dan A. Hanafi. 2001. Penentuan lokasi budidaya keramba jaring apung dengan aplikasi penginderaan jauh dan sistem informasi geografis (studi kasus di Teluk Parepare, Sulawesi Selatan). Dalam Sudradjat et al., 2001. Teknologi Budidaya Laut dan Pengembangan Sea Farming di Indonesia. Departemen Kelautan dan Perikanan dan JICA. p. 43-56. 
I N. Radiarta, Wardoyo, S.E., Priono, B., dan Praseno, O.

Lampiran 1. Gambar Teluk Ekas pada saat air surut dan pasang

Appendix 1. General feature of low tide and high tide at Ekas Bay

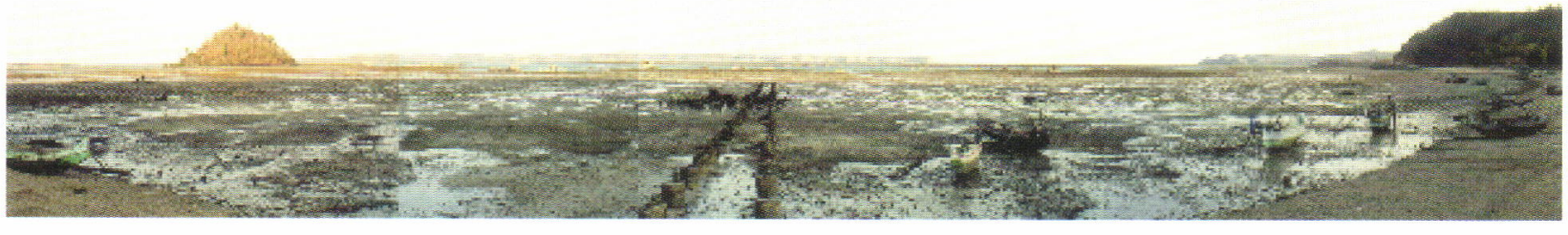

Air surut (Low tide)

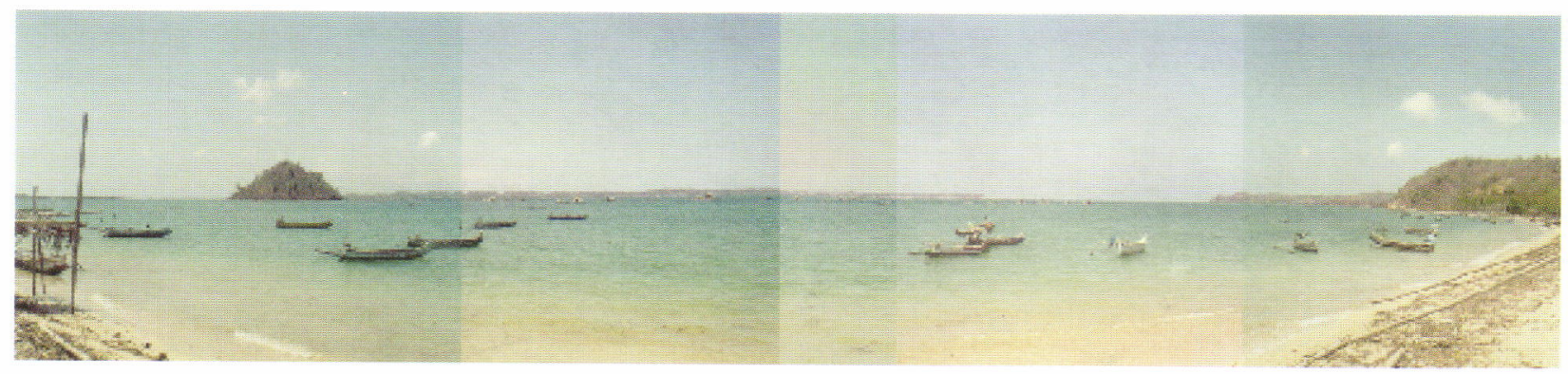

Air pasang (High tide) 
Lampiran 2. Karakteristik 56 titik di perairan Teluk Ekas

Appendix 2. Characteristic of 56 points obvervation at Ekas Bay

\begin{tabular}{|c|c|c|c|c|c|c|c|c|}
\hline $\begin{array}{c}\text { Stasiun } \\
\text { Pengamatan } \\
\text { Sampling } \\
\text { Station }\end{array}$ & Longitude & Latitude & $\begin{array}{l}\text { Kedalaman } \\
\text { Water Depth } \\
(\mathrm{m})\end{array}$ & $\begin{array}{l}\text { Kecerahan } \\
\text { Transparency } \\
\text { (m) }\end{array}$ & $\begin{array}{c}\text { Arus air } \\
\text { Water Current } \\
(\mathrm{m} / \mathrm{m})\end{array}$ & $\begin{array}{l}\text { Salinitas } \\
\text { Salinity } \\
\text { (ppt) }\end{array}$ & $\begin{array}{c}\text { Suhu Air } \\
\text { Water } \\
\text { Temperature } \\
\left({ }^{\circ} \mathrm{C}\right)\end{array}$ & $\mathrm{pH}$ \\
\hline 1 & $1,164,099$ & $-88,545$ & 9 & 4 & 16 & 25 & 30 & 8.4 \\
\hline 2 & $1,164,218$ & $-88,668$ & 2 & 2.7 & 6 & 33 & 29 & 8.4 \\
\hline 3 & $1,164,111$ & $-88,518$ & 2.2 & 3.5 & 7 & 30 & 29 & 8.4 \\
\hline 4 & $1,164,125$ & $-88,443$ & 1.5 & 1.5 & 9 & 35 & 30 & 8.4 \\
\hline 5 & $1,164,160$ & $-88,409$ & 0.8 & 1 & 6 & 34 & 29 & 8.5 \\
\hline 6 & $1,164,160$ & $-88,409$ & 1.3 & 1 & 8 & nd & 29 & 8.5 \\
\hline 7 & $1,164,174$ & $-88,385$ & 1.3 & 0.8 & 7 & 35 & 30 & 8.4 \\
\hline 8 & $1,164,198$ & $-88,373$ & 1.2 & 1 & 7 & nd & 29 & 8.5 \\
\hline 9 & $1,164,217$ & $-88,346$ & 0.8 & 0.9 & 7 & 35 & 28 & 8.4 \\
\hline 10 & $1,164,217$ & $-88,344$ & 0.8 & 0.5 & 12 & 35 & 29 & 8.4 \\
\hline 11 & $1,164,250$ & $-88,331$ & 1.6 & 0.9 & 8 & 34 & 30 & 8.5 \\
\hline 12 & $1,164,276$ & $-88,339$ & 1.8 & 1 & 8 & 34 & 29 & 8.4 \\
\hline 13 & $1,164,301$ & $-88,344$ & 1 & 1.1 & 6 & 35 & 29 & 8.5 \\
\hline 14 & $1,164,327$ & $-88,352$ & 0.8 & 0.8 & 6 & 35 & 30 & 8.5 \\
\hline 15 & $1,164,364$ & $-88,658$ & 8.8 & 4.25 & 2 & 38 & 25 & nd \\
\hline 16 & $1,164,412$ & $-88,634$ & 15.2 & 4.25 & 3 & 39 & 25 & nd \\
\hline 17 & $1,164,461$ & $-88,602$ & 2.5 & 2.5 & 6 & 39 & 25 & nd \\
\hline 18 & $1,164,503$ & $-88,566$ & 10.8 & 3 & 3 & 37 & 24.5 & nd \\
\hline 19 & $1,164,558$ & $-88,513$ & 7 & 2.6 & 3 & 37 & 24 & nd \\
\hline 20 & $1,164,597$ & $-88,474$ & 2.3 & 2 & 2 & 37 & 25 & nd \\
\hline 21 & $1,164,548$ & $-88,459$ & 8.9 & 3.4 & 1 & 37 & 25 & nd \\
\hline 22 & $1,164,504$ & $-88,452$ & 8.9 & 3 & 3 & 38 & 27 & nd \\
\hline 23 & $1,164,460$ & $-88,441$ & 1.9 & 2 & 4 & 35 & 26 & nd \\
\hline 24 & $1,164,411$ & $-88,429$ & 1.9 & 1.8 & 6 & 35 & 26 & nd \\
\hline 25 & $1,164,368$ & $-88,419$ & 2 & 2 & 8 & 33 & 27 & nd \\
\hline 26 & $1,164,330$ & $-88,383$ & 5.75 & 3 & 8 & 33 & 27 & nd \\
\hline 27 & $1,164,294$ & $-88,380$ & 4.7 & 2.6 & 8 & 37 & 27 & nd \\
\hline 28 & $1,164,251$ & $-88,396$ & 3 & 2.4 & 9 & 36 & 26 & nd \\
\hline 29 & $1,164,130$ & $-88,532$ & 11.1 & 3 & 2 & 36 & 26 & nd \\
\hline 30 & $1,164,035$ & $-88,668$ & 5 & 2 & 12 & 40 & 28.5 & 8 \\
\hline 31 & $1,164,124$ & $-88,668$ & 15 & 5 & 10 & 40 & 28.5 & 8 \\
\hline 32 & $1,164,124$ & $-88,848$ & 24 & 3 & 5 & 39 & 28 & 8.13 \\
\hline 33 & $1,164,124$ & $-88,938$ & 30 & 5 & 2 & 39 & 28 & 8.41 \\
\hline 34 & $1,164,214$ & $-88,578$ & 23 & 3.5 & 7 & 41 & 29 & 7.5 \\
\hline 35 & $1,164,214$ & $-88,668$ & 3.4 & 3.4 & 18 & 39 & 28 & 7.5 \\
\hline 36 & $1,164,214$ & $-88,758$ & 25 & 5 & 11 & 40 & 28 & 8 \\
\hline 37 & $1,164,214$ & $-88,848$ & 23 & 5 & 10 & 40 & 28 & 7.5 \\
\hline 38 & $1,164,214$ & $-88,938$ & 37.2 & 7 & 8 & 40 & 28 & 8.2 \\
\hline 39 & $1,164,304$ & $-88,578$ & 25 & 5 & 11 & 41 & 28.5 & 7.5 \\
\hline 40 & $1,164,304$ & $-88,668$ & 26 & 4 & 10 & 39 & 28 & 7.5 \\
\hline 41 & $1,164,304$ & $-88,758$ & 7 & 7 & 8 & 40 & 28 & 8 \\
\hline 42 & $1,164,304$ & $-88,848$ & 21.5 & 7 & 8 & 40 & 28 & 7.5 \\
\hline 43 & $1,164,304$ & $-88,938$ & 37.5 & 5 & 11 & 40 & 28 & 8 \\
\hline 44 & $1,164,394$ & $-88,578$ & 19 & 4.5 & 16 & 40 & 28 & 8 \\
\hline 45 & $1,164,394$ & $-88,668$ & 20 & 3 & 10 & 39 & 28 & 8 \\
\hline 46 & $1,164,394$ & $-88,758$ & 24 & 6 & 9 & 40 & 28 & 8 \\
\hline 47 & $1,164,394$ & $-88,848$ & 19 & 5 & 10 & 39 & 28 & 8.5 \\
\hline 48 & $1,164,394$ & $-88,938$ & 33.8 & 8 & 5 & 40 & 28 & 8 \\
\hline
\end{tabular}


IN. Radiarta, Wardoyo, S.E., Priono, B., dan Praseno, $O$.

\begin{tabular}{ccccccccc}
\hline 49 & $1,164,484$ & $-88,488$ & 9 & 2 & 7 & 39 & 29 & 8 \\
50 & $1,164,484$ & $-88,578$ & 13 & 3.5 & 6 & 40 & 28 & 8 \\
51 & $1,164,484$ & $-88,668$ & 17 & 3.5 & 7 & 40 & 28 & 8 \\
52 & $1,164,484$ & $-88,758$ & 1 & 1 & 18 & 40 & 28 & 8 \\
53 & $1,164,484$ & $-88,848$ & 16 & 5 & 18 & 40 & 28 & 8 \\
54 & $1,164,484$ & $-88,938$ & 3 & 3 & 8 & 40 & 28 & 8 \\
55 & $1,164,574$ & $-88,488$ & 7 & 1 & 6 & 39 & 29 & 8 \\
56 & $1,164,404$ & $-88,531$ & 0.5 & 0.5 & 8 & 40 & 29 & 8 \\
\hline
\end{tabular}

